CUPAUAM 23, 1996, pp. 191-211

\title{
LOS ALTOS DEL RINGO RANGO (LOS BARRIOS, CÁDIZ): UN COMPLEJO RESIDENCIAL E INDUSTRIAL DE ÉPOCA ROMANA (SS. I-V D.C.) EN LA BAHÍA DE ALGECIRAS
}

\author{
Darío Bernal Casasola \\ LOURDES LORENZO MARTINEZ \\ Dpto. de Prehistoria y Arqueología \\ Universidad Autónoma de Madrid.
}

\section{Resumen}

El objetivo de nuestro trabajo es dar a conocer los resultados preliminares obtenidos en la intervención arqueológica de urgencia llevada a cabo en el mes de Julio de 1998 por un equipo de la Universidad Autónoma de Madrid en la villa romana de Puente Grande, integrada en los Altos del Ringo Rango, en el Término Municipal de Los Barrios (Cádiz), con motivo de la realización de un acceso de la Autovía A-381 a dicha localidad, en la cual se pusieron al descubierto algunas estructuras murarias. Se presenta un avance de la documentación obtenida durante el trabajo de campo, cuya excepcionalidad radica en tratarse del primer asentamiento de época romana destinado a la explotación agropecuaria y de los recursos marítimos del entorno excavado de manera sistemática hasta la fecha en el Campo de Gibraltar. Los restos documentados coinciden con un sector de la pars urbana del asentamiento, así como diversas dependencias que inducen a pensar en la existencia de un posible complejo termal de época altoimperial (ss. I-II d.C.). Asimismo, el hallazgo de un horno destinado a la fabricación de ânforas, cerámicas comunes y material latericio en el s. IV d.C. confirma la reocupación de que fue objeto la villa en el Bajo Imperio, la cual ha sido detectada en la práctica totalidad de las zonas excavadas hasta la fecha.

\section{Summary}

The purpose of this paper is to present the preliminary results of a rescue excavation carried out in July 1998 by a team of the Universidad Autónoma of Madrid in the site so called "los Altos del Ringo Rango", placed in the village of Los Barrios, in the modern province of Cádiz. The work was planned due to the construction of a new road to the city centre of Los Barrios from the A-381 highway. We present an advance of the archaeological results that have confirmed the existence of a roman site focused on the maritime and agricultural explotation of the field in the Campo de Gibraltar. The remains, exceptional as they are the only ones of such a site sistematically excavated in this area, are linked with the pars urbana of a villa, as well as some rooms and structures related to baths of early Roman times (I-II c. a.d.). The finding of a pottery kiln producing amphorae, common pottery and bricks in the IV century a.d. and other rooms excavated confirm the re-ocupation of the site in late roman times. 


\section{INTRODUCCIÓN}

El yacimiento de los Altos del Ringo Rango ya se conocía con anterioridad a la realización de la intervención arqueológica de urgencia cuyos resultados preliminares presentamos en estas páginas. Diversas noticias aportadas por investigadores locales nos pusieron en antecedentes sobre la aparición de restos arqueológicos en el entorno meridional inmediato al casco urbano de Los Barrios, en una zona de notable extensión conocida con el topónimo del Ringo Rango (figura 1 A). En las III Jornadas de Historia del Campo de Gibraltar se dieron a conocer en un trabajo monográfico los hallazgos de época altoimperial en la vega del Ringo (BERNAL 1995), los cuales nos ponían sobre la pista de la importancia del asentamiento en época clásica. A estas noticias debemos sumar los hallazgos documentados posteriormente y dados a conocer por D. Mariscal en la prensa local y en publicaciones de carácter regional, que ya alertaron sobre la aparición de restos arqueológicos en una zona hoy muy cercana a la trayectoria de la autovía A-381 en dirección Los Barrios-Jerez de la Frontera. La construcción del primer tramo de la autovía A-381 a principios de los años noventa puso al descubierto una serie de pavimentos, estructuras murarias y restos cerámicos diversos en posición primaria que confirmaban la existencia de un yacimiento romano de notable envergadura en las inmediaciones de la finca conocida como Cortijo Grande. Posteriores tareas de remodelación del área de protección de la autovía, especialmente la realización de una zanja para facilitar el drenaje de las aguas, afectaron de nuevo al yacimiento. La construcción de un acceso de la autovía A-381 al casco urbano de los Barrios ha propiciado la realización de esta excavación arqueológica, la cual ha estado encaminada a plantear las medidas de conservación del yacimiento y a delimitar su perímetro, al tiempo que se han excavado algunos sondeos en diversos puntos del yacimiento, por lo que nuestro conocimiento de los restos arqueológicos preservados es aquilatado.

En este trabajo que aquí se presenta pretendemos dar a conocer por primera vez los resultados obtenidos en la excavación arqueológica llevada a cabo en el mes de julio en los Altos del Ringo Rango (Los Barrios, Cádiz), especialmente los relacionados con la documentación de una villa romana, denominada de Puente Grande, fechada inicialmente en época augustea, y cuya vida perdura hasta finales del s. I o principios del s. II d.C. En ella se ha podido comprobar la existencia de algunos habitáculos de la pars urbana, así como toda una serie de estancias destinadas a usos industriales diversos. De este mismo período también data una gran piscina, a modo de natatio, así como toda una serie de elementos indirectos que permiten confirmar la existencia de unas termas romanas relacionadas con la villa altoimperial. Este asentamiento romano se reocupa en el Bajo Imperio, y durante esta segunda etapa se llevaron a cabo algunas remodelaciones en las estancias altoimperiales, así como en la citada natatio, utilizada como almacén. También de estas mismas fechas se ha podido constatar la presencia de un complejo alfarero por la aparición de un horno destinado a la fabricación de ánforas, cerámicas comunes y material latericio, en un momento avanzado del s. IV d.C. A tenor de los resultados de las excavaciones realizadas hasta la fecha, el asentamiento se abandonó en época tardorromana, avanzado el s. V d.C.

En la intervención arqueológica llevada a cabo en los Altos del Ringo Rango se pudieron documentar dos fases, una fase altoimperial con dos horizontes constructivos (Fase IA y IB) y otra bajoimperial, denominada Fase II. A continuación procedemos a una descripción 
general de los principales hallazgos por fases, remitiendo al informe de la intervención para los detalles técnicos (BERNAL y LoRenzo 1998) y a las Actas de las V Jornadas de Historia del Campo de Gibraltar para la ampliación de estos resultados (BERNAL y LORENZO 1998B).

Durante el trabajo de campo han sido definidas diversas áreas de excavación, denominadas sectores, cuya numeración es correlativa por letras de la A a la $\mathrm{H}$, y cuya situación espacial aparece reflejada en la figura 2. Para facilitar la comprensión general de los hallazgos en los siguientes apartados aludimos a los restos por sectores, al tiempo que realizamos en cada caso una sucinta valoración general de los hallagos.

\section{LOS HALLAZGOS DE ÉPOCA ALTOIMPERIAL (SS. I Y II D.C.)}

Los restos arqueológicos más antiguos documentados en la villa de Puente Grande datan de época medio-augustea, momento a partir del cual se documenta el mayor auge de este centro de explotación agropecuaria, pues han aparecido hallazgos del s. I d.C.

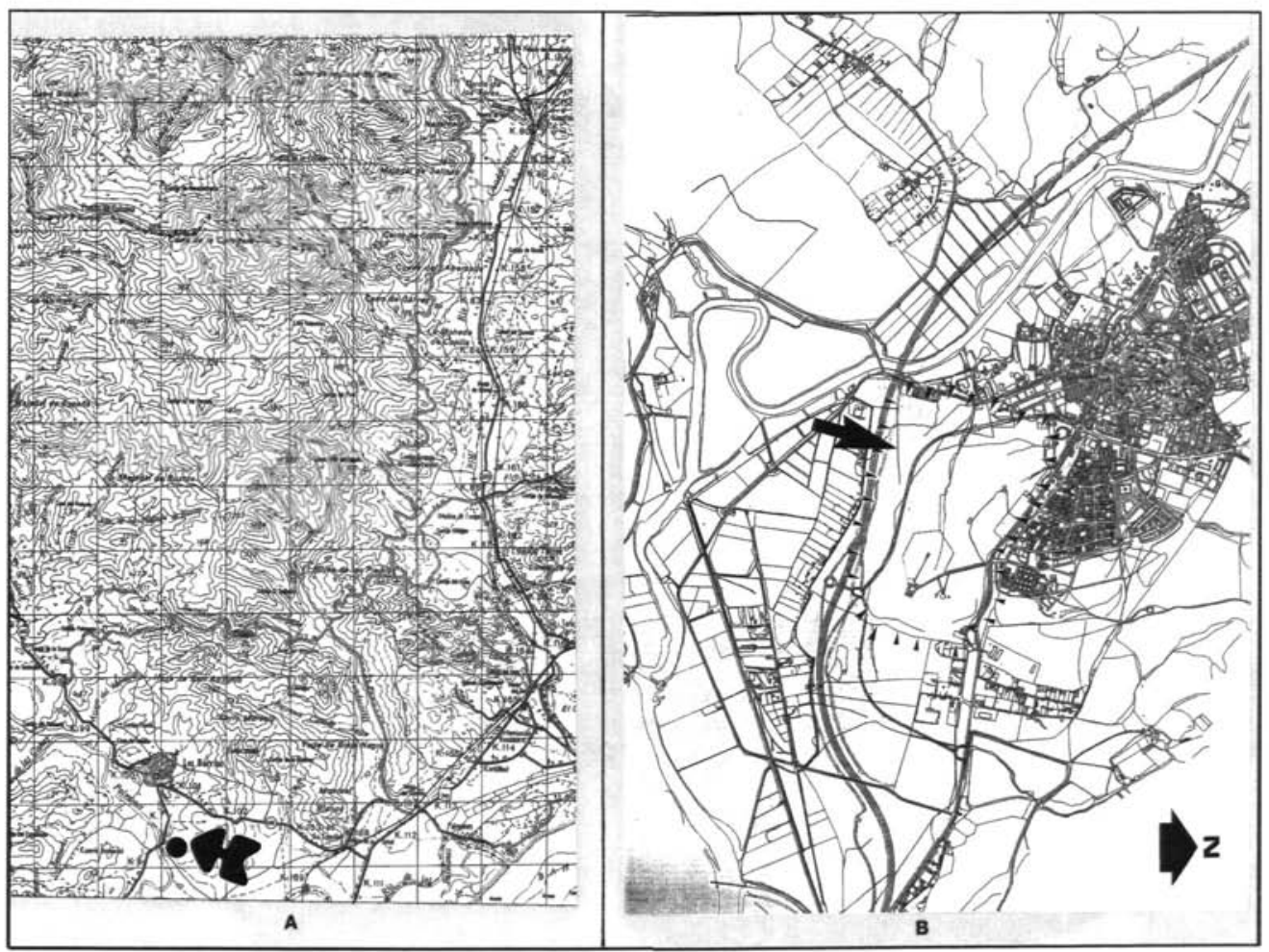

Figura 1. Localización del yacimiento del Ringo Rango en relación con el caso urbano de Los Barrios (A) y ubicación del mismo en el plano a escala 1:10.000 de la localidad (B). 


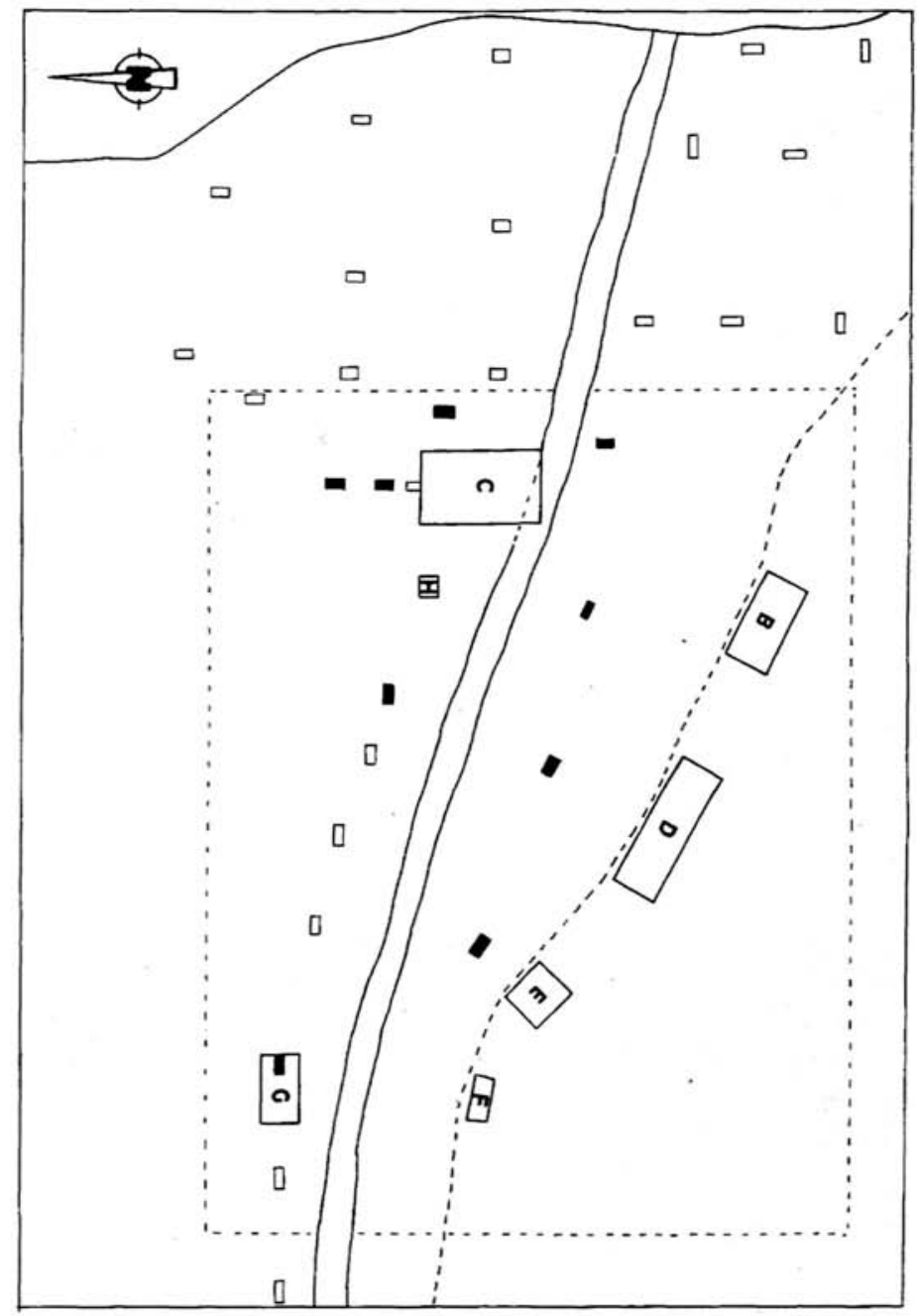

Figura 2. Detalle de los sectores definidos durante el trabajo de campo. 
El sector A se encuentra notablemente separado del núcleo que ha proporcionado los restantes hallazgos, situándose a unos ochocientos metros al este de la villa romana. Se ha localizado en esta zona una estructura muraria fechada en época altoimperial, tanto por la técnica constructiva empleada, a base de grandes sillares de piedra trabados con argamasa, como por la aparición de un ánfora del tipo Beltran II A como parte del núcleo de ripios de la construcción. La presencia de un revestimiento externo en este caso de opus signinum confirmaba esta atribución, al tiempo que permitía relacionarla con los restos de una estructura vinculada con el suministro o la captación de aguas. En las inmediaciones se localizaron una serie de unidades murarias de cronología moderna (ss. XVII-XIX), que también en esta ocasión constituían estructuras aisladas, no relacionándose con ningún otro resto visible en superficie en un radio de decenas de metros a la redonda (figura 3).

La interpretación planteada para estas estructuras aisladas es compleja, ya que han aparecido desmochadas y en un pésimo estado de conservación, al documentarse prácticamente en superficie. Su relación con una surgencia de agua parece evidente, máxime si atendemos a la existencia de un pozo en las inmediaciones y a la elevación del freático en esta zona de los Altos del Ringo Rango. Resulta plausible la relación de esta estructura romana con un punto de aprovisionamiento hídrico, del cual se nutriría la villa, o al menos una parte de ella, en época altoimperial. Es por ello que probablemente constituya parte del castellum aquae de un acueducto, o quizás los restos muy deteriorados de una fuente de notables dimensiones, si atendemos a la grandiosidad de la construcción. La búsqueda de restos arqueológicos en las inmediaciones que permitieran contrastar la primera de las hipótesis ha sido infructífera.

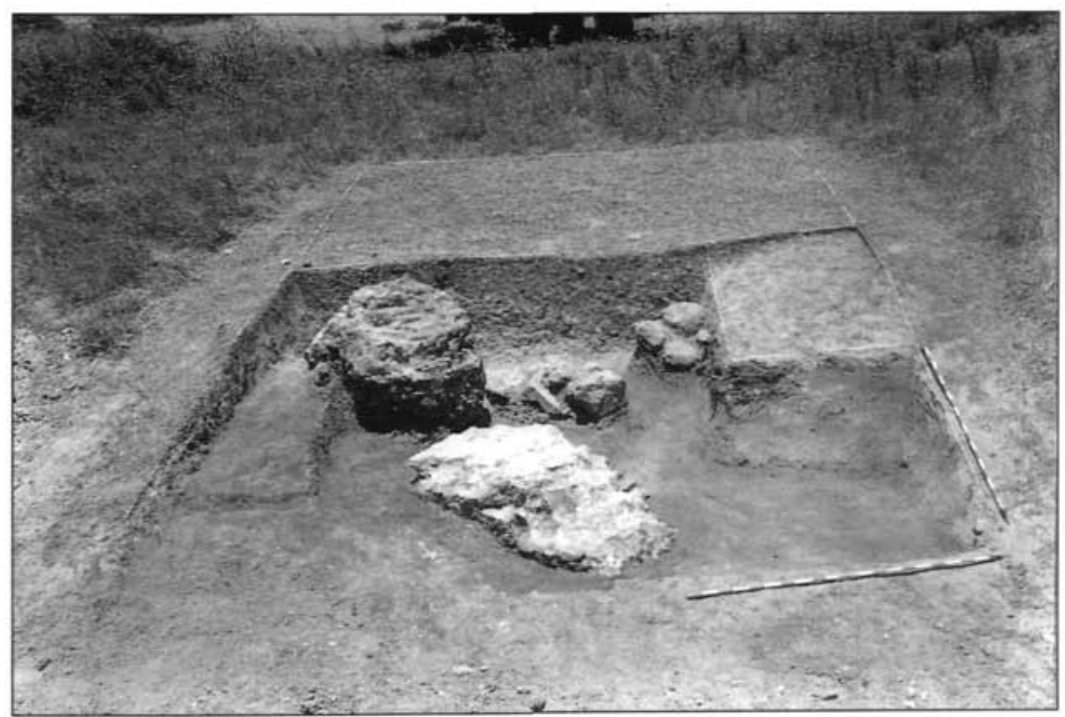

Figura 3. Vista general de las unidades murarias aparecidas en el sector A. 
El epicentro de los hallazgos de la villa romana se centra en los restantes sectores excavados (B, C, D, E, F, G y H), los cuales se circunscriben a una zona de unos $5000 \mathrm{~m}^{2}$, estando íntimamente relacionados entre sí (figura 2). Los hallazgos constatados en el sector B también han permitido documentar dos fases constructivas nítidamente diferenciadas, la primera de ellas correspondiente con el momento inicial de la villa romana de Puente Grande. Pertenecientes a la primera fase constructiva o fase IA, aparecieron dos estructuras murarias completamente arrasadas por construcciones posteriores, cuya técnica constructiva empleaba mampuestos de caliza de medianas dimensiones trabados entre sí con barro. Dichas estructuras conformaban un ángulo recto, delimitando una estancia relacionada con una unidad de habitación, si atendemos al grosor de los muros y a la cuidada técnica constructiva documentada en su ejecución. Los restos de cultura material aparecidos, básicamente TSI -y la ausencia significativa de barnices negros o cerámicas pintadas, y la datación ante quem que le podemos aplicar a estas estructuras al haber aparecido bajo las de la Fase IB-, han permitido fechar el inicio del asentamiento en época augustea o tiberiana.

En cuanto a la segunda fase constructiva o IB, se documentó desde el inicio de la intervención arqueológica la existencia de una serie de unidades murarias de notable envergadura, cercana al metro de anchura (figura 4), las cuales hacían pensar en la existencia de varias habitaciones relacionadas con la zona residencial del complejo, la pars urbana de la villa altoimperial. La aparición de multitud de restos de vajilla fina, en proporciones elevadísimas en relación con las restantes zonas de la excavación, así como los hallazgos de numerosas lucernas, vidrio y restos metálicos en los niveles de amortización de estas habitaciones permitían reforzar dicha propuesta inicial. Se ha excavado una parte significativa de estas estructuras, cercana a los $25 \mathrm{~m}^{2}$, habiéndose documentado dos unidades murarias que corren paralelas en dirección norte-sur, definiendo una serie de espacios rectangulares (figura 5). La técnica constructiva de los muros se compone de mampuestos de notables dimensiones trabados con argamasa, apareciendo los laterales enlucidos con cal, sin estucado exterior conservado. La pavimentación de estas estancias es bastante pobre, compuesta por tierra apisonada y guijarros de pequeñas dimensiones, estos últimos posiblemente pertenecientes a la gravera de la paleoterraza del río Palmones sobre la cual se asienta el yacimiento que nos ocupa. La excavación sistemática de los niveles de colmatación de estas habitaciones ha permitido constatar el proceso de abandono del yacimiento en época romana. Se ha documentado el derrumbe de la techumbre, según se desprende de la presencia en la U.E. 108 de gran cantidad de restos constructivos, mayoritariamente tégulas e imbrices. La cantidad de restos de cultura material aparecidos en los niveles inferiores ha permitido una datación bastante aquilatada, como es el caso de la U.E. 109, algunos de cuyos hallazgos ilustramos en la figura 6. En el caso de la vajilla fina se han documentado numerosas formas de TSH, básicamente platos del tipo $15 / 17$, y copas de la forma $24 / 25$ y 27 , estas últimas con diversas marcas. Son especialmente frecuentes los hallazgos de TSG, con formas propias del repertorio habitual tales como las Drag. 24/25, 27 y las 29 decoradas, mayoritariamente del taller de La Graufesenque. Se ha documentado la aparición minoritaria de algunas formas iniciales del repertorio de la TSA de la producción $A^{1}$, normalmente la Lamboglia 1 y la 3 (ATLANTE I 1981), con decoración burilada exterior en el borde. Las lucernas aparecidas pertenecen a la familia de las de volutas, siendo especialmente frecuentes las de rostrum con doble voluta desarrollada (tipo Dr. 11), las cuales conviven con algunos tipos iniciales de la familia de disco, 


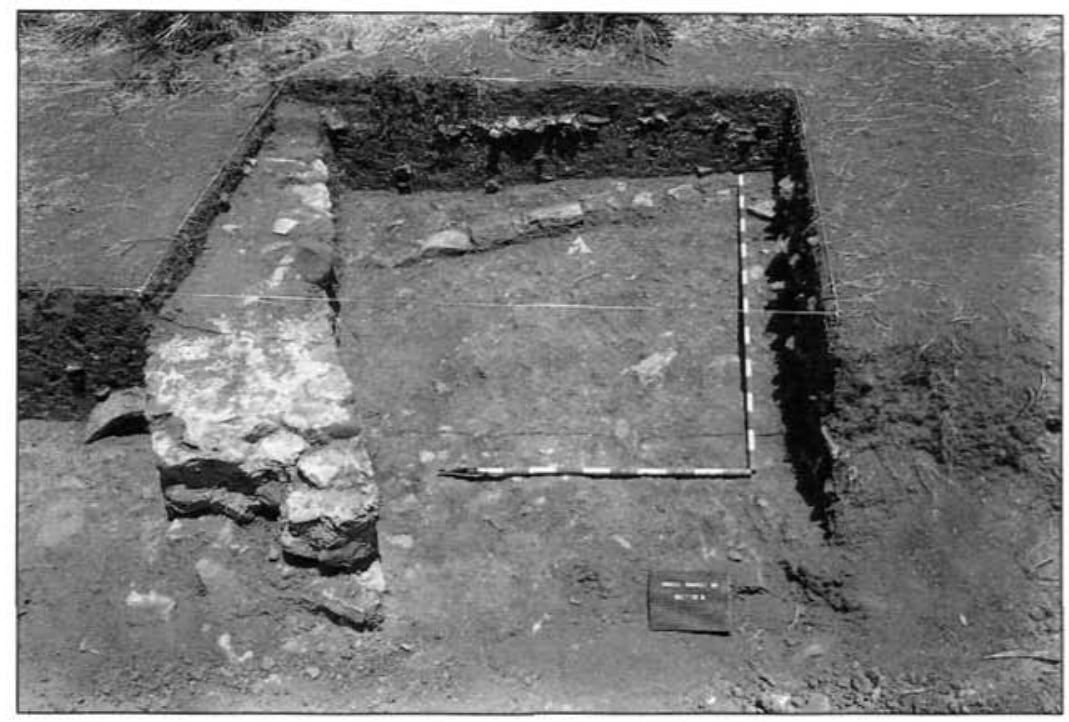

Figura 4. Detalle del proceso de excavación de las habitaciones del Sector B relacionadals con la pars urbana de la villa altoimperial.

especialmente la Dr. 20 (Morilo 1990). Las tazas y cubiletes de paredes finas aparecidas, así como las abundantes formas de africanas de cocina (Ostia III, 267; Lamboglia 10 A...) contribuyen a fechar el momento de uso de estas estructuras. A pesar de que el estudio de los restos exhumados aún está en fase preliminar proponemos un inicio para esta fase en un momento aún impreciso de mediados del s.I d.C., fecha de ampliación de las estructuras de la villa, perdurando su uso hasta época de Cómodo o principios del s.II d.C., momento en el que el sector se abandonó por completo, hasta su reocupación dos siglos más tarde, en plena época bajoimperial. Esta zona ha sido interpretada como el área de hábitat del asentamiento, y posiblemente en la misma se situaba la parte residencial del complejo, lugar de hábitat del dominus y de los propietarios del fundus en el que se integraba la villa.

Los hallazgos más significativos de época altoimperial se han documentado en el denominado sector $\mathbf{C}$, situado en la zona más elevada del pequeño cerro sobre el cual se sitúa el yacimiento (figura 7). Los restos excavados en este sector se corresponden posiblemente con la segunda fase constructiva localizada en el sector B, fechada, grosso modo, en la segunda mitad del s. I d.C. Los hallazgos en este sector se corresponden con los restos de una piscina de grandes dimensiones compuesta de cuatro muros trabados entre sí, que definen un espacio rectangular de unos $60 \mathrm{~m}^{2}$ (12 x $5 \mathrm{mts}$. aproximadamente), tal y como ilustramos en la figura 8. En uno de los lados cortos de la misma (M-108) apareció un pequeño canal de desagüe compuesto por calizas adoveladas, las cuales permitían la evacuación de agua hacia la parte septentrional de la estructura. La técnica constructiva de los muros de esta posible natatio o euripus está formada por pequeños guijarros o cantos de la paleoterraza infraya- 


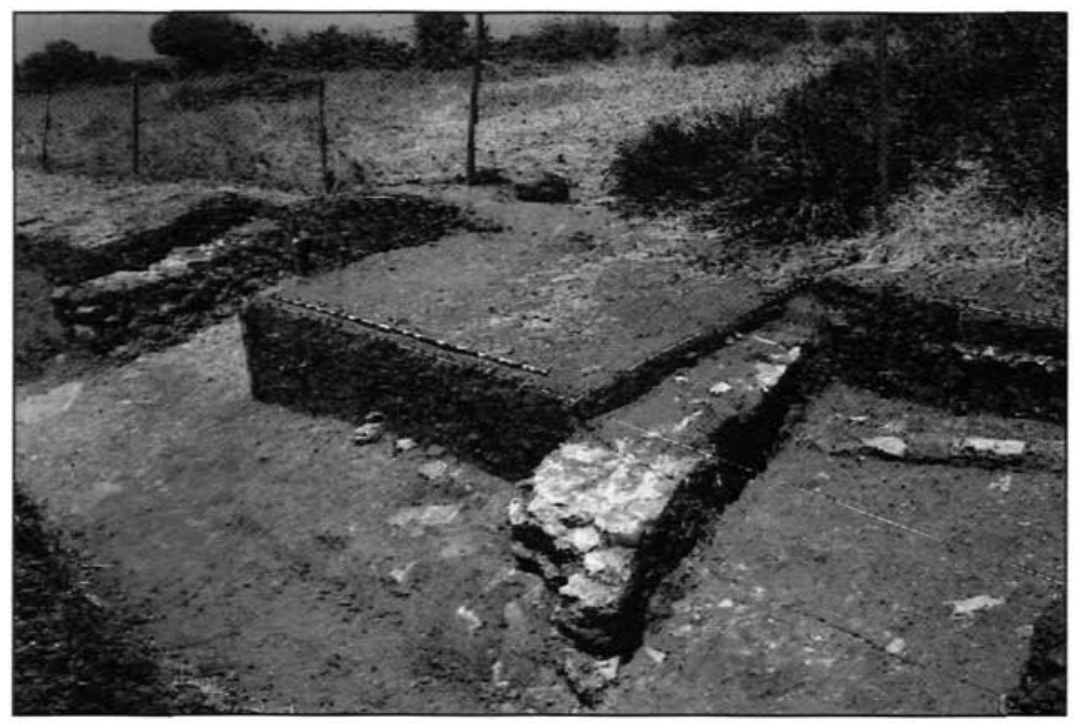

Figura 5. Sector B. Vista general al final de la intervención arqueológica.

cente trabados entre sí con argamasa y cal, generando una estructura muy sólida, con muros cercanos al metro de grosor. Toda la estructura se encuentra recubierta con hormigón hidráulico, un opus signinum de muy buena calidad, utilizado para la impermeabilización de la misma, por lo que su relación con el agua es evidente. La pavimentación de este estanque también está recubierta por signinum, y las uniones entre el. suelo y la pared de la piscina están invariablemente recorridas por pequeñas molduras de cuarto de bocel, a todo lo largo de su perímetro, similares a las conocidas piletas de las factorías de salazones (PONSICH 1988). El estado de conservación de esta estructura es notable, y en algunos lugares se ha conservado una altura de los paramentos cercana al metro. No han aparecido restos de la escalera que sin duda debió facilitar el acceso a la misma, la cual debió estar posiblemente situada en la zona suroeste, coincidiendo con el sector en el cual no se conserva el alzado del muro perimetral oeste de la piscina.

En cuanto a la interpretación posible para esta estructura de notables dimensiones, las posibilidades son diversas. Partimos de la base de que el revestimiento a base de hormigón hidráulico permite afirmar que esta estructura debió estar en contacto con agua, al tratarse del típico revestimiento impermeabilizante utilizado a estos efectos en época romana. Se planteó inicialmente su relación con un aljibe destinado a la contención de agua, si bien tras la excavación nos vimos obligados a abandonar dicha posibilidad ya que la estructura es prácticamente aérea, detalle inviable para una piscina de estas características, las cuales siempre son excavadas en el subsuelo. Además, debido al volumen de agua almacenado en una construcción de esta índole, los muros perimetrales tendrían un grosor mucho mayor del pre- 


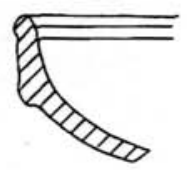

1
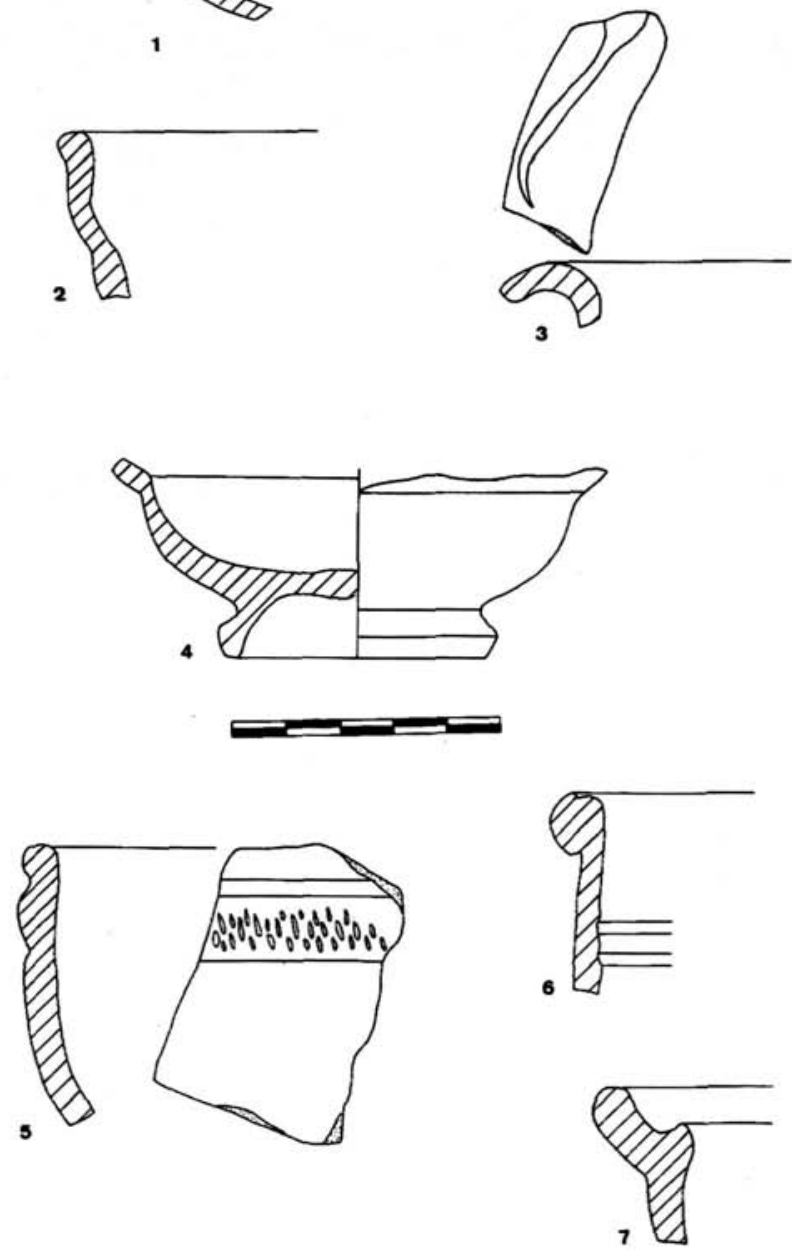
Figura 6. Materiales de época altoimperial procedentes de la U.E. 109 (Sector B). Fragmentos de TSG (1.- Drag.
24/25; 4.- Drag. 27), de TSH (2.- forma 27; 3.- forma 36 con hoja de agua), TSA A (5.- Lamboglia 3) $y$ africanas de cocina (6.- Ostia III, 267; 7.- Ostia II,302). 


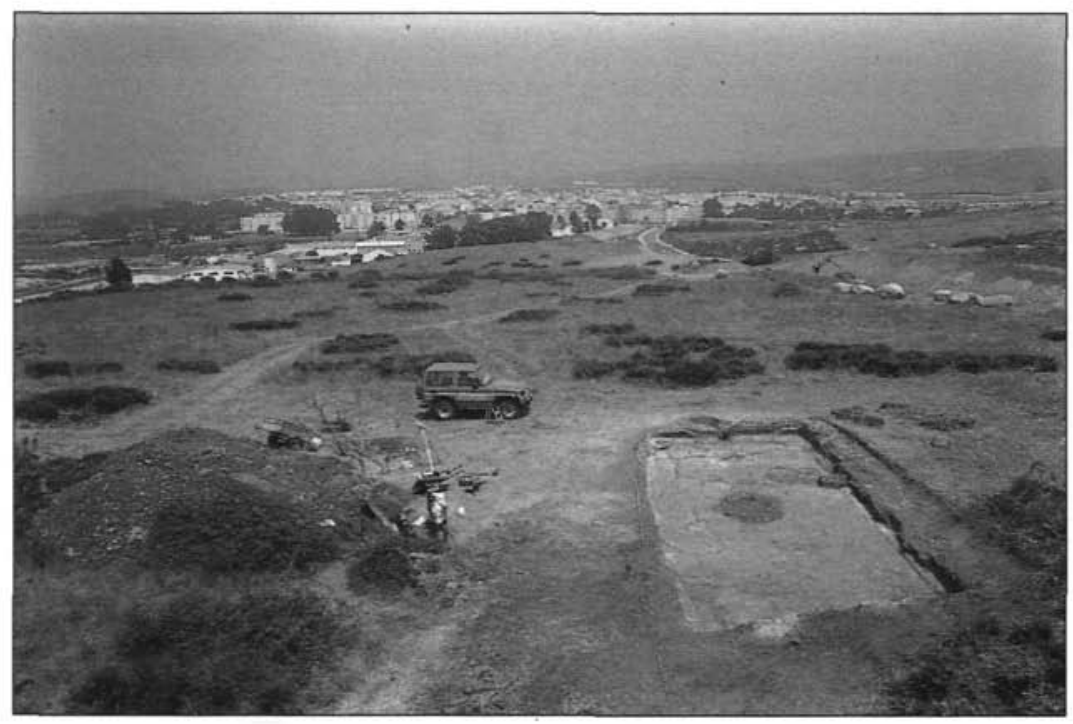

Figura 7. Detalle del proceso de excavación del sector C, con la aparición de la piscina con revestimiento de hormigón hidraúlico.

servado, al estar destinados a contener tensiones laterales de envergadura. La segunda hipótesis es que se tratase de un receptáculo de agua de notables dimensiones, el cual, a modo de alberca, habría servido para la captación y contención de aguas, probablemente para el ganado o para tareas de irrigación. No obstante, la depurada técnica constructiva de la estructura y sus notables dimensiones tampoco permiten pensar que esta sea la hipótesis mas viable de todas. Quizás se trate de un estanque monumental, integrado en la zona residencial de la vivienda, si bien por el momento no contamos con argumentos de peso para decantarnos por tal posibilidad.

La última posibilidad planteada es que nos encontremos ante una natatio de notables dimensiones, relacionada con un establecimiento de tipo termal. La interpretación que creemos más viable por el momento es la última, pues además contamos con una serie de argumentos indirectos que permiten conocer la existencia de unas termas en la villa de Puente Grande. Nos referimos a la aparición en diversos puntos de la excavación de ladrillos troncoapiramidados o con orejetas cuya relación con la creación de concamerationes de las estancias calefactadas de las termas es evidente (BRODRIBB 1987; VV.AA. 1998). El hallazgo de estos ladrillos y además la aparición en el lugar hace años de varias clavijas de doble pared parecen demostrar la existencia de un complejo termal en época altoimperial. Por otro lado, la realización de una serie de fosas en el s. IV d.C. permitió documentar la inexistencia de hipocaustos bajo el suelo de esta gran piscina, por lo que probablemente se trata de una natatio de agua fría. Solamente sorprenden las notables dimensiones de esta estructura, que se alejan de las habituales asociadas a las natationes conocidas (NIELSSEN 1990). Esta hipóte- 


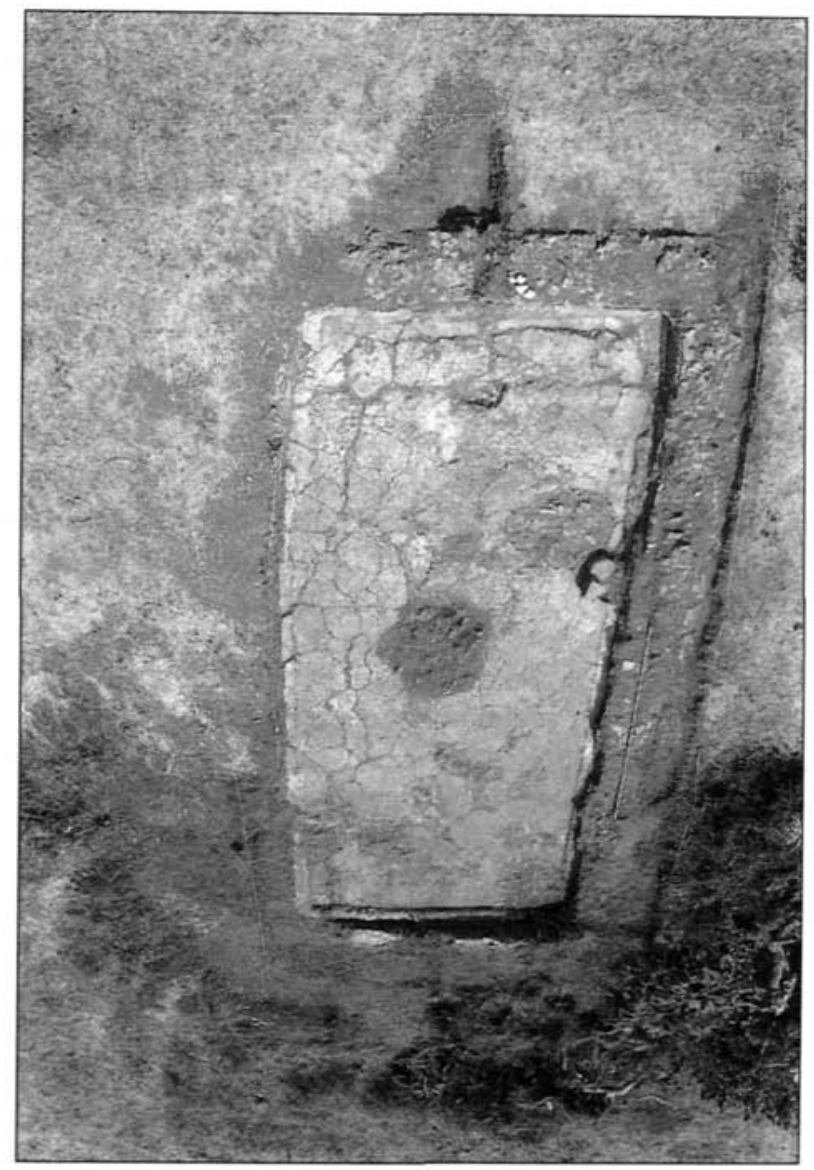

Figura 8. Vista aérea de la posible natatio, de planta rectangular, al final de la intervención arqueológica.

sis, que deberá ser refrendada en el futuro con más hallazgos, es la que parece más viable en la actualidad, y que permite relacionar esta estructura con los restos de unas termas privadas de época altoimperial, las cuales formarían parte de las estructuras de la villa de Puente Grande, en directa relación espacial con la pars urbana del asentamiento campogibraltareǹo.

De época altoimperial también se han documentado restos arqueológicos en el sector D. Se ha constatado la existencia de una estructura muraria que posiblemente pertenecería a otra de las habitaciones o estancias de la villa, en relación con las habitaciones aparecidas en el sector B, ya que dicho sector se ubica en las inmediaciones. La técnica constructiva emple- 
ada es de las mismas características que el resto de los habitáculos, a base de mampuestos de caliza y arenisca de medianas dimensiones trabados entre sí con barro. El grado de conservación de la misma es bastante precario y se encuentra casi destruida, al aparecer prácticamente en superficie, siendo cubierta por niveles sedimentarios que escasamente superan en medio metro de potencia. La pavimentación de esta estancia es de opus signinum, y confirma la continuidad del asentamiento hacia el oeste, con habitaciones de notables dimensiones cuya cronología, basada en los materiales integrados en el nivel de derrumbe del propio muro y en los recuperados en el nivel de colmatación situado directamente sobre la pavimentación (TSH, TSA A, ánforas diversas) permiten pensar en un momento avanzado del s. I y principios del s. II para su abandono.

En el sector $\mathbf{E}$ se ha documentado una estructura muraria que apareció casi destruida debido a su situación en superficie, además del hecho de haber sido afectada por una zanja perimetral para la evacuación de aguas realizada por medios mecánicos hace varios años. Su técnica constructiva, coincidente con la de las restantes estructuras exhumadas en el Ringo Rango, es a base de mampuestos de notables dimensiones y ripios de tamaño variable trabados con barro. También en el sector $\mathbf{F}$ se documentaron los restos de una estructura prácticamente destruida, que confirma la continuidad de la villa hasta este punto, y que como en el caso anterior asociamos a época altoimperial, siendo el material datante más relevante algunas formas de TSA A.

\section{LA REOCUPACIÓN DEL ASENTAMIENTO EN EL BAJO IMPERIO (sS. IV y V d.C.)}

En cuanto a la fase bajoimperial son muy pocos los restos conservados en el yacimiento por el momento, en relación con la fase precedente. Solamente se han documentado hallazgos de estas fechas en alguno de los sectores excavados, básicamente el sector B, C, D y $G$, ya que la mayor parte de estos restos se han perdido al aparecer prácticamente en superficie y únicamente cubiertos por el nivel vegetal superficial. No obstante, su interés es vital para el conocimiento de este establecimiento rural, ya que se confirma una reocupación de la villa de Puente Grande en el s. IV d.C., y además con un carácter similar al de época precedente: los restos recuperados se relacionan con actividades industriales de diverso tipo, por lo que la vocación primigenia del asentamiento se mantuvo al menos hasta el final de época bajoimperial.

En el sector $\mathbf{B}$ hemos podido documentar hallazgos de época bajoimperial en una de las habitaciones excavadas. Concretamente nos referimos a la aparición de una pavimentación realizada con tégulas fragmentadas, restos de ladrillos y tierra apisonada creando así una superficie plana y homogénea. Esta pavimentación sólo se ha localizado en la zona noreste de dicho sector, y en relación también con esta estructura se ha documentado un pequeño murete de escasa entidad. Dicho muro se encuentra situado sobre una estructura de época altoimperial, y fue realizado mediante un simple recrecimiento del mismo en altura y, por tanto, utilizando este muro como zapata de la unidad muraria bajoimperial (figura 9). La técnica constructiva empleada es completamente distinta a la utilizada en la fase anterior, pues en estos momentos se emplearon en la construcción mampuestos de roca metamórfica y caliza de grandes dimensiones con los cantos redondeados, utilizando barro y no argamasa como en el muro sobre el cual se asienta como aglutinante. No es posible determinar la fun- 
cionalidad de esta estancia, si bien las notables dimensiones de la misma y el aspecto poco cuidado de la pavimentación hacen pensar en usos relacionados posiblemente con tareas agropecuarias tales como almacenes de aperos de labranza, de la cosecha o bien una amplia zona para la estabulación del ganado. En cuanto a la cronología propuesta para esta fase de reocupación, contamos tanto con la datación post quem de finales del s. I o principios del s. II proporcionada por la cronología de los niveles infrayacentes de la fase anterior y por los materiales situados directamente sobre los niveles de colmatación de la pavimentación, que al aparecer prácticamente en superficie, proporcionaron restos de época imperial diversa. No obstante, los hallazgos de los sectores limítrofes y la excavación en el sector D de una pavimentación similar permitieron a posteriori fechar estas estructuras en época bajoimperial, entre el s. IV y un momento indeterminado del s. V d.C., en espera del estudio definitivo de los materiales.

En el sector C la documentación de la Fase II es de mayor envergadura y está constituida por los niveles relacionados con la reforma de que fue objeto la supuesta natatio de época altoimperial. Tras el abandono de la villa en el s. II d.C. el lugar permaneció inalterado hasta su reocupación en el s. IV d.C. Fue en dicho momento en el cual se documentaron las primeras actividades edilicias en la misma basadas en la realización de una serie de fosas, en total tres de distintos tamaños, en el suelo de la piscina. La funcionalidad de las mismas no está muy clara, si bien posiblemente se destinasen a documentar los restos inferiores bajo la pavimentación, pues esta estructura había sido abandonada con casi dos siglos de antelación. Posteriormente a la realización de las mismas éstas fueron cubiertas de nuevo, y sin dejar prácticamente restos dignos de mención (a excepción de algunos fragmentos de fuentes de TSA D con decoración estampada de los primeros estilos de Hayes), se allanó el terreno dejándolo coincidente con la cota del suelo, momento a partir del cual se comenzaron a reutilizar estas estructuras. A tenor de los hallazgos de dolios de medianas dimensiones para tareas de almacenaje y multitud de ánforas de diversas procedencias (béticas, africanas, orientales) pensamos que esta gran habitación rectangular se destinó a servir de almacén de mercancías diversas, para lo cual se la dotó de una techumbre realizada a base de tégulas, según se desprende del hallazgo de un pequeño muro tabiquero adosado a la parte central de su muro perimetral este (M-112) y, sobre todo, por la documentación del nivel de derrumbe del mismo durante el proceso de excavación (figura 10). La piscina estaba totalmente colmatada por un nivel que interpretamos como de derrumbe del techo y de las paredes de dicha estancia tras su abandono al final del Bajo Imperio. Posiblemente el desplome de la techumbre fuera inmediatamente posterior al abandono de la habitación ya que han aparecido integrados en la matriz de este nivel algunos materiales arqueológicos situados sobre el suelo de la piscina, como sucede con la fuente de TSA D que ilustramos en la figura 11. Adicionalmente se ha documentado el pequeño murete cuadrangular adosado al muro perimetral este ya citado, construido con un posible fuste circular retallado y mampuestos unidos entre sí con barro. Posiblemente esta estructura constituya el zócalo de un elemento de sustentación para la cubierta. El canal de desagüe de la piscina también estaba relleno por un nivel de época bajoimperial.

La cronología que proponemos para la reutilización de la piscina coincide inicialmente con el momento en el cual se realizaron las fosas, y que podemos fechar en el s.IV d.C., si atendemos a los restos de TSA D recuperados. El momento de abandono de estas estructu- 
ras vendría determinado por el colapso de la techumbre y de las paredes, que guiados por la aparición de TSA D, ánforas africanas, béticas -Dr.23- y orientales -L.R.1- (KFAY 1984) y numerosos restos monetales aún en estudio, debemos situar en un momento avanzado del s. $\mathrm{V}$ d.C., en espera de que culmine el estudio definitivo de los restos de cultura material exhumados. En cuanto a la funcionalidad que tendría esta habitación en el bajoimperio, y como ya hemos comentado, pensamos que sería un lugar de almacén de mercancías, el cual estaría además cubierto, guiados por el derrumbe de la techumbre, así como por el elemento de sustentación encontrado. Además en el interior de la estancia han aparecido una serie de dolios de medianas dimensiones con fondo plano y ánforas de transporte que parecen corroborar esta hipótesis.

En el sector D se ha documentado una pavimentación hecha a base de tégulas reutilizadas colocadas horizontalmente, al tiempo que en algunos lugares estos materiales latericios

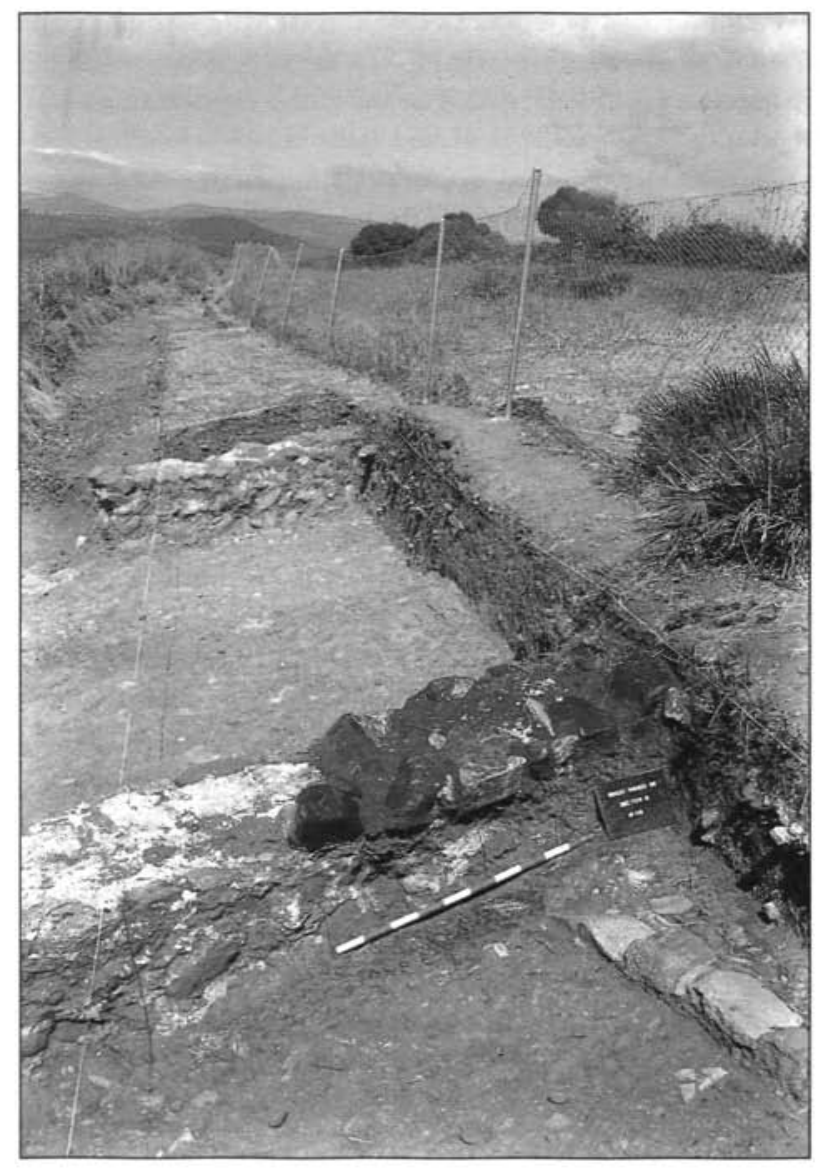

Figura 9. Recrecimiento de época bajoimperial del muro M-104 del sector B (=M-119). 
desaparecen y simplemente se ha allanado el terreno, apisonando su capa superior. Este suelo ha sido fechado gracias al material encontrado en el nivel de colmatación del mismo, compuesto mayoritariamente por vajilla fina africana (las últimas producciones de TSA D) y ánforas tardorromanas sudhispánicas del tipo Almagro 51C (KeAY 1984). Este suelo es de las mismas características que el encontrado en el sector $\mathrm{B}$, y la cronología propuesta para ambos se sitúa entre el s. IV y el V d.C., atendiendo a la dinámica general de la ocupación de la villa tardorromana. La pobreza y poca entidad constructiva del mismo induce a ponerlo en relación con las estructuras de la pars rustica de la villa.

El sector $\mathbf{G}$ ha proporcionado estructuras de época bajoimperial de gran envergadura. La totalidad de los hallazgos se relacionan con la aparición de un horno de pequeño tamaño destinado a la cocción de cerámica común, ánforas de transporte y material latericio, así como algunas estructuras relacionadas con actividades diversas de alfarería. El descubrimiento del mismo se debió a la necesidad de documentar el perímetro del yacimiento, para lo cual se procedió a la realización de una serie de sondeos con medios mecánicos, siendo éste caso uno de los cuales que depararon resultados positivos. El notable enrojecimiento que presentaban los niveles geológicos infrayacentes ya nos pusieron sobre la pista de la posibilidad de la aparición de un horno en las inmediaciones. El horno excavado es de planta ovalada, de 1,5 mts. en su eje mayor y $1 \mathrm{mt}$. en el menor, presentando un característico praefurnium abocinado (figura 12), respondiendo a un modelo bien conocido en numerosos yacimientos de la Bética, como sucede con algunos talleres malacitanos (BAENA 1997). El estado de conservación del horno es moderado, conservándose únicamente la cámara de combustión y el arranque de la parrilla. Para la realización del horno se procedió a excavar una fosa en el substrato geológico con la forma en negativo del horno. La cámara de combustión fue recubierta de ladrillos cuadrangulares, generando un forrado que cubría la totalidad de la superficie del horno, como en el caso de los alfares malagueños de la Huerta del Rincón (SERRANO, BaLdomero y CASTAÑo 1991). Esta unidad construida era utilizada para facilitar la sujeción de la parrilla y de la cámara de cocción. El interés fundamental que presenta este horno radica en la cronología a la que se ajusta, situada en época bajoimperial, si nos guiamos por los hallazgos de TSA D, como sucede con la forma Hayes 61, así como por diversos restos importados. En la antesala previa al horno han aparecido una serie de niveles arqueológicos con abundante material cerámico, entre los cuales se han encontrado desechos de cocción, materiales defectuosos y cerámicas de importación africana, que nos marcan la pauta de la cronología bajoimperial que proponemos para este alfar.

Los materiales que se fabricaban en este horno se componen, una vez más, de la trilogía compuesta por materiales latericios, sobre todo tégulas y ladrillos, ánforas de transporte y cerámicas comunes diversas. Entre las ánforas, son las destinadas al envasado de salazón de pescado y sus derivados las más abundantes, siendo el tipo claramente individualizado la Almagro 51C. También se ha documentado una forma recientemente definida en otros contextos de producción, caracterizada por presentar un perfil tubular muy característico, relacionada con los envases denominados Majuelo I (BERNAL 1997), destinadas asimismo al procesado de las salazones. También se ha documentado la imitación de ánforas africanas, como sucede con las denominadas Keay VI, siendo este el tercer alfar de la Bética en el cual se ha documentado esta práctica, junto a Los Barreros en Salobreña, en la costa granadina, y Puente Melchor en Puerto Real, en la Bahía gaditana (Bernal. 1998; Garcia VARGas y LaVAdo 


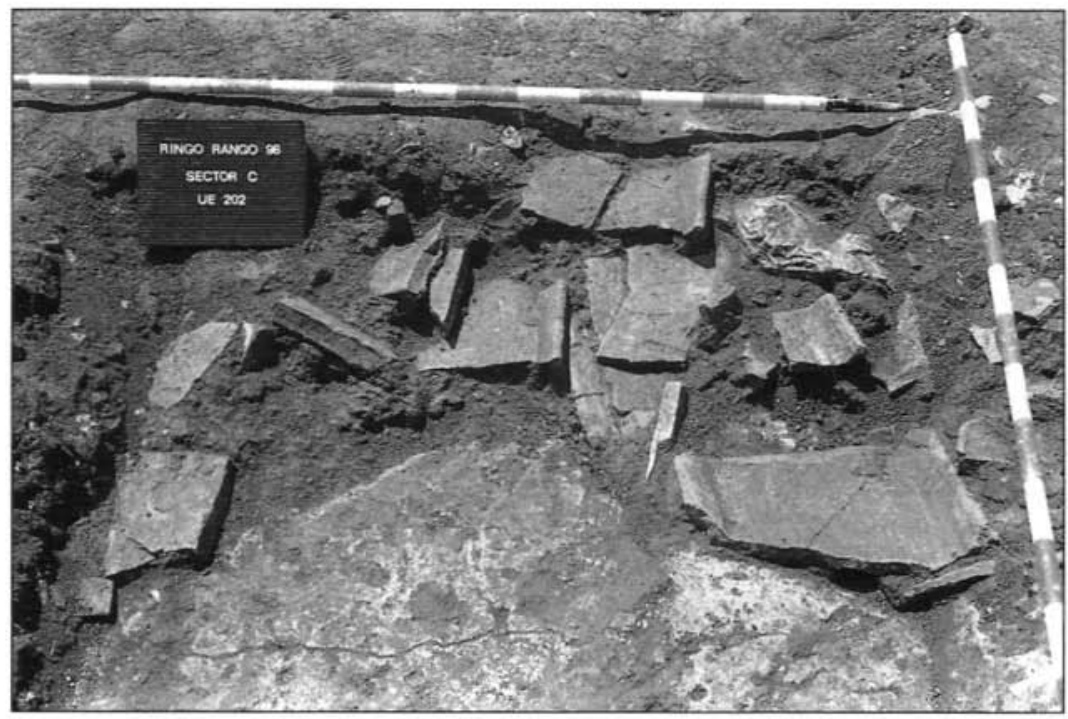

Figura 10. Derrumbe de la techumbre de tégulas del almacén del Sector C.

1997). La tipología de las cerámicas comunes de producción local no es muy amplia, entre las cuales se han documentado algunas formas abiertas.

Los materiales arqueológicos recuperados en el interior del horno, formando parte de los niveles de colmatación del mismo tras su abandono (U.E. 603, 604) han permitido documentar su producción cerámica, aún en proceso de estudio, pero de vital interés para el conocimiento de las actividades económicas realizadas en la Bahía de Algeciras en los últimos momentos de la dominación romana, y pocas décadas antes de la dominación bizantina de la zona.

Debido al carácter excepcional de esta estructura y en colaboración con diversos colegas del Dpto. de Física de la Tierra I de la Universidad Complutense de Madrid se realizó un estudio por arqueomagnetismo de su estructura interna (figura 13), para conseguir de esta manera afianzar los resultados de un proyecto de trabajo en curso para toda la Península Ibérica (NúNEz et alii 1998).

\section{CONCLUSIONES}

El objetivo propuesto con estas páginas no es otro que presentar a la comunidad científica los resultados preliminares de la Intervención Arqueológica de Urgencia desarrollada en verano de 1998 en Los Altos del Ringo Rango. Como avance preliminar, nos hemos limitado a realizar una presentación inicial de los hallazgos, centrándonos en los restos de la villa 


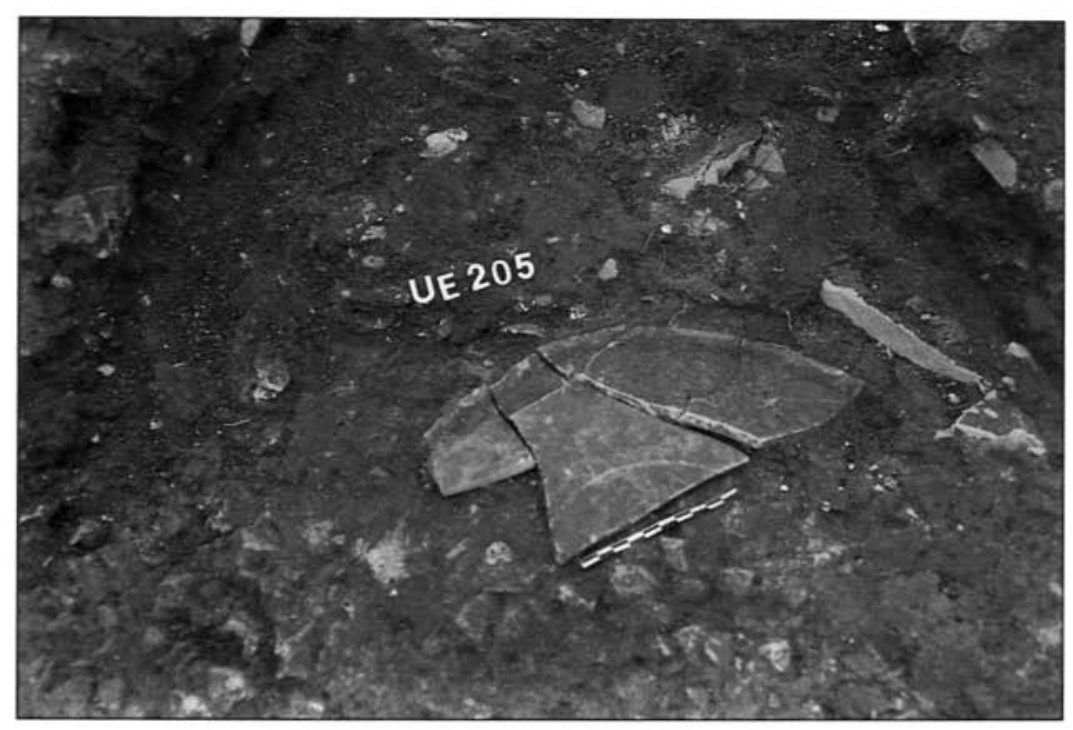

Figura 11. Detalle de la aparición de una fuente de TSA D decorada con motivos estampados sobre el suelo de signinum de la piscina del sector $\mathrm{C}$, en la fase de reocupación bajoimperial.

romana de Puente Grande, sin duda el yacimiento más importante de la totalidad de la zona objeto de la intervención. En la actualidad está siendo realizada la Memoria Científica de la excavación por parte de un equipo interdisciplinar de la Universidad Autónoma de Madrid y de algunos miembros del Instituto de Estudios Campogibraltareños, si bien hasta la publicación del texto definitivo consideramos conveniente presentar un avance de los hallazgos arqueológicos efectuados en esta localidad gaditana.

La construcción de la villa romana se remonta a época augustea avanzada o quizás coincidiendo con el reinado de Tiberio, si bien de estos primeros momentos solamente hemos documentado algunos restos constructivos en el Sector B, y materiales cerámicos en posición secundaria en diversas zonas del yacimiento. Coincidiendo probablemente con unos momentos de mediados del s. I d.C. se produce una ampliación de las estructuras existentes, dotando a las mismas de mayor entidad y ampliando posiblemente la extensión del establecimiento primigenio. A esta época corresponden la mayor parte de los restos de época altoimperial exhumados, los cuales debemos relacionar con la posible pars urbana de la villa (Sector B), una serie de habitaciones de notable extensión anejas de funcionalidad incierta (Sector D, E, F) y una piscina revestida con hormigón hidráulico que hemos relacionado con una posible natatio de un complejo termal. Los hallazgos de material latericio invariablemente relacionado con complejos termales y las características propias de esta estructura hacen pensar en su posible relación con unas termas privadas de notable entidad. No obstante, y a pesar de plantear esta posibilidad como hipótesis de trabajo, habrá que esperar a 
nuevas intervenciones arqueológicas que permitan aclarar y arrojar luz a estas propuestas. En el Campo de Gibraltar son escasos los hallazgos de complejos termales, siendo los más conocidos los de la ciudad punico-romana de Carteia (PRESEDO y CABAllos 1988; Roldán 1992) y los de la ciudad de Baelo Claudia (ETIEnNE y MAYET 1971; Sillières 1995), por lo que nos encontraríamos antes las terceras termas conocidas y excavadas en la totalidad del Campo de Gibraltar, y las primeras relacionadas con un establecimiento no urbano.

Da la impresión, al menos a tenor de la documentación proporcionada por la intervención arqueológica desarrollada, que el yacimiento se abandona muy a finales del s. I o bien a principios del s. II d.C., según se ha documentado especialmente en los niveles de colmatación de la habitaciones excavadas en los sectores B y D. Desde entonces, la villa de Puente Grande fue posiblemente abandonada hasta la reinstalación de contingentes humanos en el s. IV d.C. Hasta la fecha carecemos por tanto de documentación para plantear una continuidad del asentamiento en el s. III d.C. Con el Bajo Imperio se sitúa en los Altos del Ringo Rango un establecimiento muy similar al de época altoimperial, y de él han llegado hasta nosotros restos de diversas habitaciones quizás relacionadas con estabulación del ganado (Sectores B y D), pero en cualquier caso con fines productivos y/o industriales. Especialmente significativo ha sido el hallazgo de un gran almacén u borreum en el sector C, reaprovechando las estructuras de la piscina de época precedente. El hallazgo de un horno fechado en estos momentos presenta unas jugosas expectativas de futuro para la investigación, al tratarse del primer horno de estas características fechado en el Bajo Imperio en la Bahía de Algeciras (BERNAl 1998B), y uno de los escasísimos en la Andalucía costera.

Las actividades productivas desarrolladas en la villa romana de Puente Grande, en los Altos del Ringo Rango, estaban en íntima relación con la agricultura, según denuncia la presencia de algún molino de cereal, con el aprovechamiento pecuario, si pensamos en las posibles estancias para la estabulación del ganado y, sobre todo, con la explotación de los recursos marítimos, si pensamos en la cercanía de la línea de costa y del curso del río Palmones. Efectivamente la aparición de anzuelos para la pesca y la fabricación de ánforas destinadas al comercio de salazones y salsas de pescado constituyen argumentos de peso de notable envergadura. Por último, resulta de gran interés la aparición de gran cantidad de restos de escorias metálicas y útiles elaborados que hacen pensar en la realización de actividades destinadas a la obtención de instrumentos de hierro en las dependencias de este asentamiento campogibraltareño.

La villa de Puente Grande constituye el primer asentamiento rural de estas características excavado en el Campo de Gibraltar. La entidad de los restos aparecidos es ilustrativa por sí sola, y la notable extensión del yacimiento, si bien notablemente inferior a la totalidad de su perímetro original por los destrozos de que ha sido objeto, evidencia el interés científico del mismo para el conocimiento de la ocupación y explotación del territorio en época romana en esta parte del Conventus Gaditanus. En la actualidad están siendo arbitradas desde la Delegación Provincial de la Consejería de Cultura de la Junta de Andalucía en Cádiz las medidas convenientes para la protección y conservación de los restos exhumados. El interés desde el Ayuntamiento de Los Barrios por la conservación de su patrimonio histórico-arqueológico ha dado una vez más sus frutos. Esperamos en los próximos años dar buena cuenta 


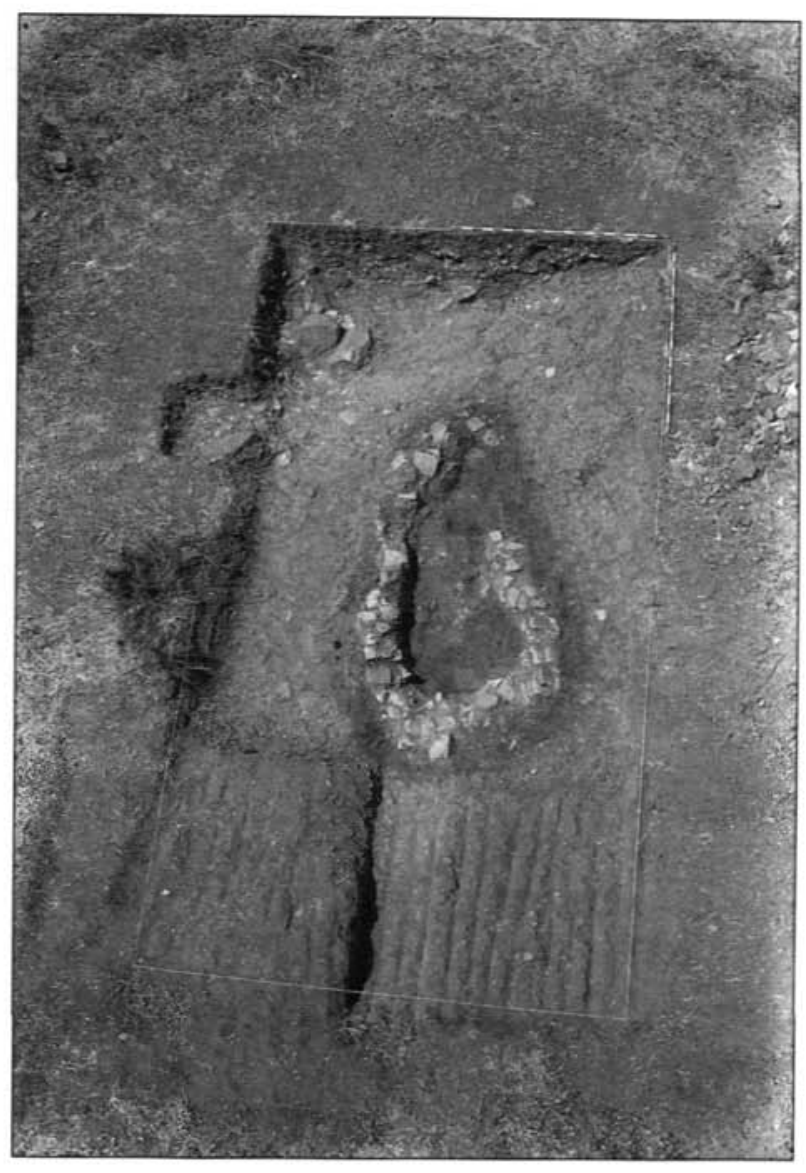

Figura 12. Vista aérea del horno del s. IV d.C.

de los resultados de esta investigación, cuya relación con la vecina Carteia y con los restantes asentamientos de la Bahía de Algeciras es prueba de la integración territorial que tras la Pax instaurada por Augusto se vivía en el día a día en el entorno de las provincias occidentales del imperio. Este yacimiento se sitúa en primera línea, junto a la Colonia Latina Libertinorum (RoLDÁN et alii 1998) entre los asentamientos gaditanos y del "Círculo del Estrecho" cuya productividad científica se muestra reveladora para los próximos años. 


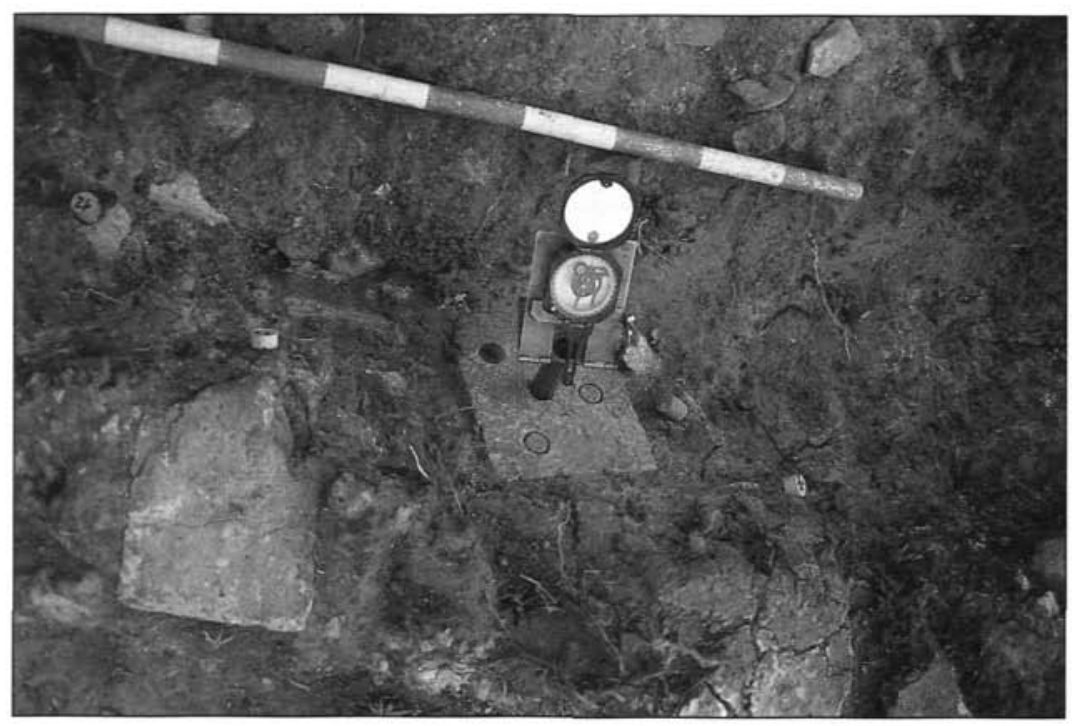

Figura 13. Datación por arqueomagnetismo del horno del Sector D. Detalle de la orientación de las muestras con brújula solar.

\section{BIBLIOGRAFÍA}

ATLANTE I (1981): VV.AA., Atlante delle forme ceramiche, I, Ceramica fina romana nel bacino mediterraneo (medio e tardo impero), Supplementum dell'Enciclopedia dell'Arte Antica, Classica ed Orientale, Roma.

BAFNA DEl AlCÁzAR, L. (1997): "Arquitectura y tipología de los hornos romanos malacitanos", Figlinae malacitanae, La producción de cerámica romana en los territorios malacitanos, pp. 95-106.

Bernal Casasola, D. (1995): "Un nuevo yacimiento en el Término Municipal de Los Barrios: los materiales romanos de la vega del Ringo Rango", III Jornadas de Historia del Campo de Gibraltar (La Línea de la Concepción 1994), Almoraima 13, pp. 117-129.

Bernal CASASOla, D. (1997): Economía y comercio de la Bética mediterránea y del Círculo del Estrecho en la Antigüedad Tardía (ss. III-VII d.C.) a través del registro anfórico, Tesis Doctoral microfichada, Universidad Autónoma de Madrid.

Bernal Casasola, D. (1998): Los Matagallares (Salobreña, Granada). Un centro romano de producción alfarera en el s. III d.C., Ayuntamiento de Salobreña, Salobreña.

Bernal CASASOla, D. (1998B): Excavaciones arqueológicas en los alfares romanos de la Venta del Carmen (Los Barrios, Cádiz). Una aproximación a la producción anfórica en la Babia de Algeciras en época romana altoimperial, Universidad Autónoma de Madrid y Ayuntamiento de Los Barrios, Madrid. 
Bernal Casasola, D. Y Lorenzo Martínez, L. (1998): "Informe de la Intervención Arqueológica de Urgencia en Los Altos del Ringo Rango (Los Barrios, Cádiz)", Anuario de Arqueología Andaluza 1998, Sevilla.

Bernal Casasola, D. Y Lorenzo Martínez, L. (1998B): "El poblamiento de época romana en Los Barrios (Cádiz). Resultados preliminares de la intervención arqueológica en Los Altos del Ringo Rango", V Jornadas de Historia del Campo de Gibraltar (Algeciras, Octubre 1998), en prensa.

BRODRIBB, G. (1987): Roman brick and tile, Gloucester.

ETIENNE, R. y MAYET, F. (1971): "Briques de Belo. Relations entre la Mauretanie tingitane et la Bétique au bas-empire", Melanges de la Casa de Velázquez VII, pp. 59-69.

García VARGaS, E. y LaVAdo Florido, M.L. (1997): "Ánforas alto, medio y bajoimperiales de los alfares de Puente Melchor-Paso a nivel (Puerto Real, Cádiz)", Spal 4.

HAYES, J.W. (1972): Late roman pottery, Londres.

KEAY, S. (1984): Late roman amphorae in the western Mediterranean. A typology and economic study, The catalan evidence, B.A.R., international series 196.

MORILlo CERDÁn, A. (1990): "En torno a la tipología de las lucernas romanas: problemas de nomenclatura", Cuadernos de Prebistoria y Arqueología de la Universidad Autónoma de Madrid 17, pp.143-168.

NielsSen, I. (1990): Thermae et Balnea.

NúÑEz, J.I, D., OSETE, M.L. Y TARLING, D. (1998): "Datación por arqueomagnetismo del horno del Sector D", en Excavaciones arqueológicas en los alfares romanos de la Venta del Carmen (Los Barrios, Cádiz). Una aproximación a la producción anfórica en la Babia de Algeciras en época romana altoimperial (D. Bernal ed.), Universidad Autónoma de Madrid y Ayuntamiento de Los Barrios, Madrid.

Ponsich, M. (1988): Aceite de oliva y salazones de pescado. Factores geo-económicos de Bética y Tingitana, Universidad Complutense de Madrid, Madrid.

Presedo Velo, F. y Caballos Rufino, A. (1988): "Informe de la campaña arqueológica de 1985 en el yacimiento de Carteia (San Roque, Cádiz)", Anuario Arqueológico de Andalucia'85, II, pp. 397-393.

Roldán Gómez, L. (1992): Técnicas constructivas romanas en Carteia (San Roque, Cádiz), Cuadernos de Arquitectura Romana 1, Universidad Autónoma de Madrid.

Roldán, L., Bendala, M., Blánquez, J. y Martínez Lillo, S. (1998): Carteia, Junta de Andalucía y Universidad Autónoma de Madrid.

Serrano, E., Baldomero, A. y CAStaño, J.C. (1991): "Notas sobre la producción de ánforas en la Huerta del Rincón (Torremolinos, Málaga)", Baetica 13, pp. 149-154.

SILlĖkes, P. (1995): Baelo Claudia. Une cité romaine de Bétique, Madrid, pp. 307-324.

VV.AA. (1998): Complutum. Roma en el interior de la Península Ibérica. Catálogo de la exposición, Alcalá de Henares. 